\title{
Importance of Determination of Albuminuria in Patients with Newly Diagnosed Type 2 Diabetes Mellitus
}

\author{
Bogomolets National Medical University, Kyiv, Ukraine \\ Lev Prystupiuk MD, Liudmyla Naumova MD, Maksym Prystupiuk MD, \\ Marianna Naumova MD PhD, Oleksandr Prystupiuk MD PhD
}

\section{Introduction.}

Worldwide, patients with type 2 diabetes mellitus (T2DM) compose $90-95 \%$ of total number of diabetics. $10 \%$ of people aged under 60 years are affected with T2DM, also are $10-20 \%$ of people aged $60-69$ years, and $15-20 \%$ over the age of 70 years. The risk of diabetes may reach $30-40 \%$ during lifetime due to other factors than age. T2DM is characterised by higher development of cardiovascular lesions, which even more worsens the condition of the patient and increases the burden on the health care system. And since albuminuria is considered as a risk factor for cardiovascular complications and mortality, its determination is very important in screening programs for diabetes even after adjustment of other risk factors.

The aim of the study.

To determine the level of albuminuria in patients with actively diagnosed T2DM.

Materials and methods.

The screening for albuminuria involved 200 people aged 45-65 years, 100 males and 100 females, who during the screening for T2DM, were found to have $\mathrm{HbA1}$ c level over $6.5 \%$. Albuminuria was determined by quantitative and qualitative methods. Detection sensitivity test regarding protein is $10-15 \mathrm{mg} / \mathrm{L}$. All patients also were measured, in sitting, state for blood pressure on the shoulder by a mercury manometer.

Results.

Albuminuria was found in $20 \%$ of males and $30 \%$ of females of the study. Subjects with BP up to $160 / 90$ mmHg were found to have albuminuria in $32 \%$, and with BP over $160 / 90 \mathrm{mmHg}-68 \%$. Albuminuria was found in $13 \%$ of examined patients with $\mathrm{HbA1c}$ level $6.5-7.0 \%$, and in $27 \%$ of patients with $\mathrm{HbA} 1 \mathrm{c}$ level over $7.1 \%$.

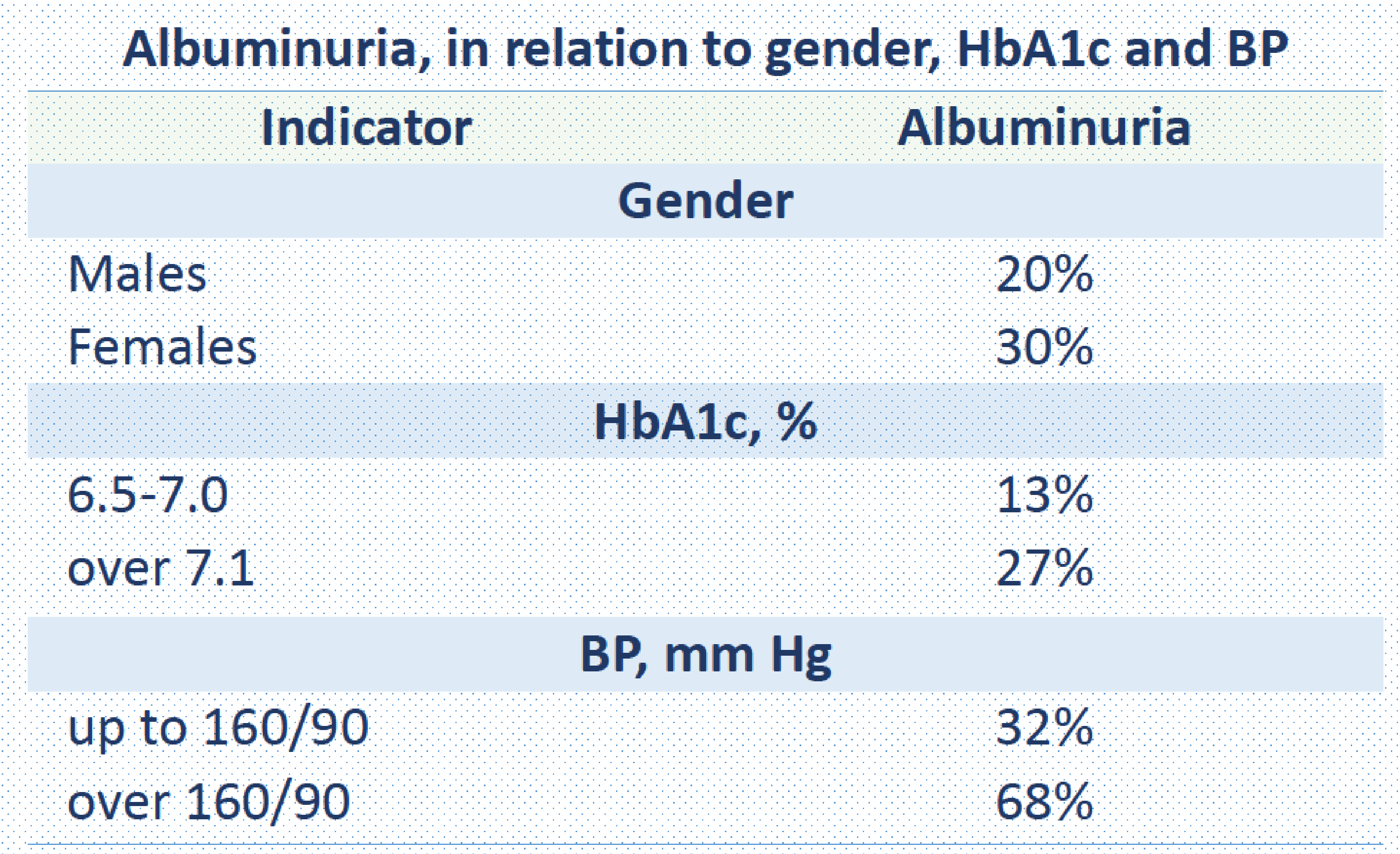

\section{Conclusions.}

1. Albuminuria was found in $20 \%$ of males and $30 \%$ of females with newly diagnosed T2DM.

2. The number of patients with albuminuria increased with $\mathrm{HbA1c}$ level over $7.1 \%$.

3. Albuminuria was diagnosed among all patients with both T2DM and hypertension. 